\title{
Accessibility for People with Cognitive Disabilities: An International Literature Review and Empirical Interview Study
}

\author{
Prof. Dr. Phil. Habil. Hendrik Trescher \\ Institute for Education Science \\ Philipps-University Marburg \\ Germany
}

\begin{abstract}
In the paper at hand, I review research of barriers and cognitive disabilities and present the analysis of expertinterviews with people with cognitive disabilities. Based upon this I discuss to what extent creating mobility that is more accessible might become challenging. The results of my study "Accessibility and cognitive disabilities", which I conducted under the auspices of the German Bundesministeriumfür Arbeit und Soziales (Federal Ministry for Labor and Social Affairs), demonstrate that only few studies are dedicated towards accessibility in the context of cognitive disabilities. This is the central result of a comprehensive literature review of English and German discourses on special needs pedagogy. Beyond discourse analysis, the study undertakes an empirical analysis of expert-interviews with60 people with cognitive disabilities. The interviews are aimed to explore where and in what contexts these people encounter barriers and what suggestions towards a more accessible environment they might have.
\end{abstract}

Keywords: accessibility; cognitive disabilities; mobility; inclusion; social environment; barriers; literature review; interview study

\section{Introduction: What does accessibility mean in the context of cognitive disabilities?}

Disability occurs as a practice whenever people encounter barriers (see Trescher, 2017a, p. 27ff; Dederich, 2012, p. 106). Barriers may emerge in practices of negotiation between a person and their environment as well as persons and other persons. Historically, an understanding of barriers and an engagement with barriers developed from the construction of barriers for people with (cognitive) disabilities which manifest concretely in (confining) institutions rooted in the principle of care (see Heck, 2012, p. 329), to the assimilation of the person with disabilities to a non-barrier-free environment based on the principle of support (see Heck, 2012, p. 329). Finally an understanding of becoming disabled through a non-accessible environment was established, which aims at deconstructing barriers to "enable unrestricted participation of social life for people with disabilities" ${ }^{1}$ Heck, 2012 , p. 330). This amounts to a "shift in responsibility for access from individuals to society" (Nind \& Seale, 2009, p. 274; see alsoSwain, French, Barnes, \& Thomas, 2004), for "although it is the individual who makes choices, it is down to society to create access" (Devas,2003, p. 234). This reduction of barriers - commonly referred to as 'accessibility' - concerns in its social context primarily persons who use wheelchairs, as apparent in the ubiquitous wheelchair pictogram synonymously used with accessibility ${ }^{2}$.

The same narrow concept of accessibility predominates on a political level: "Policy-makers engaging with the agenda of disability rights frequently adopt a discourse of access, but there are dangers of a reductionism in the concept - access being solely about ramps in public spaces and better signage" (Nind \& Seale, 2009, p. 273). For people with cognitive disabilities, however, barriers present themselves in a myriad of ways (see also Sherman \& Sherman,2013) and contribute to a (further) exclusion from a shared life world.

\footnotetext{
${ }^{1}$ Some of the literature cited is available in German language only. For a better understanding, I translated the cited parts into English. Nevertheless, the indication of source refers to the original version of the book in German.

${ }^{2}$ In the context, the use of that same wheelchair symbol as advertising websites as 'accessible' seems particularly absurd, as encountered on several occasions (see, for example, here: https://www.vg-nieder-olm.de/vg_niederolm/Aktuelles/BITV/; accessedAugust20, 2018). For a critique and the paradox of that symbol see also Dederich (2012, p. 110ff).
} 
Thus, to facilitate access for people with cognitive disabilities, "scores of barriers must be removed" (Kurzenberger, Niehoff, Walther, \& Sack, 2012, p. 126). In this context, Kastl (2010) cautions, following Shakespeare (2001), that the notion of a world without barriers is illusory and that such a comprehensive accessibility would result in a "sterile and total rearrangement" (Kastl,2010, p. 55), whereby "access [...] would be achieved at the cost of eliminating that to which access was intended" (Kastl, 2010, p. 55).

In sum, it may be argued that accessibility is primarily a moral idea, which as a definition is not without problems, since in speaking about accessibility one always invokes barriers, before subsequently pondering how to deconstruct them. Thus, accessibility denotes less the absence of barriers, as much as the will to deconstruct existing barriers. Ultimately, perception and assessment regarding accessibility may in part diverge significantly, so that questions on accessibility might well be ambivalent and, thus, warrant more thorough investigation.

Particularly in the context of cognitive disabilities the topic of accessibility, in many ways, occupies somewhat of a blank space with scant research and little theoretical and practical recognition (see, for example, Stock, Davies, Wehmeyer, \& Lachapelle, 2011; Nind\& Seale, 2009; Dean, Fisher, Shogren, \&Wehmeyer, 2016; Kurzenberger et al., 2012, p. 122) not merely concerning mobility (the focus of this paper), but also all domains of life.In this paper, I investigated barriers occurring in the context of mobility. Mobility represents an integral part of everyday life and especially affects other activities, such as work or leisure. Barriers of participation are constructed if the access to activities, for example recreational activities, is restricted by inaccessible mobility. Consequently, "no other barrier inhibits community inclusion more than the lack of appropriate, accessible, and available transportation" (Sherman \& Sherman, 2013, p. 274; see also Bitterman \& Baldwin Hess, 2008).

Conceptualizing accessibility necessarily coincides with a treatment of the location of barriers, the forms in which accessibility is intended, and the means, whereby barriers may be eliminated (see Nind \& Seale,2009).Thus, barriers "need to be recognized and understood, before they can be deconstructed" (Tervooren \& Weber, 2012, p. 11). This is especially the case, since "the barriers to accessibility faced by people with intellectual disabilities are not always apparent and, therefore, require exploration and clarification" (Yalon-Chamovitz,2009, p. 395). A deconstruction of barriers needs to be prefigured by their unveiling, since only in this way can elimination strategies be developed.This claim is a central aspect of my ongoing study in which I research accessibility in the context of cognitive disabilities. In my paper, I consider cognitive disabilities as practice of being disabled (Trescher, 2017b; 2017c). Consequently, cognitive disabilities are carried out through addressing people as cognitive disabled. "Disability is, thus, not something that can be deemed a characteristic of subjects, but rather disability is always disability of discoursive participation, which occurs in everyday interactions and practices" (Trescher, 2017c, pp. 33-34).This concept of cognitive disabilities is based on a Foucauldian understanding of discourse as practice (Foucault,1972, p. 49).

In the following section, I provide some insight into the study that serves as the basis for the present paper. Subsequently, I present and discuss selected results regarding 'mobility'. In the concluding section, I reflect on the ambivalences that may coincide with a demand to (increased) accessibility.

\section{Researching accessibility - empirical design of the study 'Accessibility and cognitive disabilities'}

The study "Accessibility and cognitive disabilities" which was conducted under the auspices of the German Bundesministeriumfür Arbeit und Soziales (Federal Ministry for Labor and Social Affairs) and in close consultation with the disability support institutions Bundesverb and Lebenshilfee. V. as well as Lebenshilfe Frankfurt am Main e.V., aims at introducing the field and providing information on (a) to what extent accessibility and cognitive disabilities are debated in specialized English and German discourses and (b) the challenges self-advocates with cognitive disabilities perceive in terms of accessibility. It is important to emphasize that the investigation assumes an understanding of accessibility relative to the life world (of the affected) and, thus, tends towards the deconstruction of the barriers within. Conceptualizing accessibility from the subject's perspective relates to a person's 'training', that is their adaption to a non-barrier-free environment, which in turn may open opportunities of participation, though this is not at issue here. Based on these key aspects a multi-layered, multi-method research design was developed, that on the one hand reviews journals and books in English and German discourses(see section 3) und on the other hand focuses on semi-structured interviews with people with cognitive disabilities (see section 4).

\section{State of Research - Results of the Literature Review}


To engage the matizing of accessibility and cognitive disabilities a literature review of specialized English and German discourses was carried out.

The review covered the period from 2007 to 2017, that is the past ten years including all publications until September 2017 (begin of research). The literature review consists of a three-step method combining quantitative and qualitative elements and was applied in the English as well as the German discourse:

- Step 1: Scanning relevant abstracts using appropriate search terms

- Step 2: Reading abstracts and assessing their relevance, scanning relevant papers

- Step 3: Reading and content analysis, inductive categorizing according to themes

Thus, 14 journals from the English discourse as well as 10 journals from the German discourse were examined as to how many and which, if any at all, contributions regarding accessibility and cognitive disabilities were published. The selection of journals was based on a list provided by the Deutsche Interdisziplinäre Gesellschaft zurFörderung der Forschungfür Menschen mitgeistiger Behinderunge.V. (DIFGB, German Interdisciplinary Society for Advocacy and Research for People with Cognitive Disabilities). The indexed journals were examined in terms of their (inter)national reach, their relevance to specialized discourse, and their thematic trajectory and selected accordingly. In the English discourse a total of 7694 contributions were included respectively, compared to 2859 contributions in the German discourse. Thus, more than 10000 contributions are tested for their pertinence to the topic of accessibility and cognitive disabilities.

In addition, two databases (ERIC - Institute of Education Science and FIS Bildung) served to search for books, anthologies, and other specialized literature, which are subsequently incorporated into the analysis and subjected to the three-step method. In a further step, (a) knowledgeable colleagues are solicited to share relevant (their own and other) contributions as well as (b) a free literature review is conducted to make sure that all possible contributions are identified and examined. In the context of journal research for the English discourse statistics show that hardly any paper about accessibility and cognitive disabilities was published. Of 7694 initially marked papers, only 54 are relevant for the topic and are incorporated into the eventual body of data (step three of the analysis) ${ }^{3}$. This amounts to only $0.7 \%$ of publications (in the analyzed journals) over the duration of the study.

The journal papers that contribute to the topic of accessibility and cognitive disabilities in the English discourse treat their object according to 14 different classifications, as illustrated in the following table:

Table 1: Classification of the articles reflecting accessibility and cognitive disabilities

\begin{tabular}{|l|l}
\hline Thematicfocusareas & Number \\
\hline School/ Education & 9 \\
\hline Social Area & 7 \\
\hline Health & 6 \\
\hline Science & 6 \\
\hline Technology & 6 \\
\hline Law/ Judiciary & 3 \\
\hline Political Participation & 3 \\
\hline Social Media/ Social Networks & 3 \\
\hline Work & 3 \\
\hline Easy Language/ Assisted Communication & 2 \\
\hline Internet & 2 \\
\hline Mobility & 2 \\
\hline Individual Support Planning & 1 \\
\hline Sexuality & 1 \\
\hline total & $\mathbf{5 4}$ \\
\hline
\end{tabular}

A first assessment shows a significant underrepresentation of important areas such as work, leisure, and particularly habitation, which receives no attention in the English discourse over the duration of the study. The main topic of this paper, mobility, is only the matized in two papers (incorporated into the analytical body of the study), which constitutes a statement about the significance accorded to the topic in the specialized discourse.

${ }^{3}$ See Trescher, $2018 \mathrm{~b}$ for comprehensive results.

62 
The 54 papers deemed relevant to the topic are analyzed in terms of three overarching questions and the results are summarized according to content. The guiding questions are:

1) What is the referenced or sketched concept of accessibility?

2) What barriers are considered in relation to the selected object and cognitive disabilities?

3) What perspectives and what required actions to develop accessibility are considered in the context of cognitive disabilities?

Using the area of mobility as an example, the following demonstrates the analytical approach in the treatment of the respective papers. Among the entire pool of materials, the only contributions engaging with accessibility and mobility in the context of cognitive disabilities are the papers "Bus rapid transit identity meets universal design" (Bitterman \& Baldwin Hess, 2008) and "Preventing mobility barriers to inclusion for people with intellectual disabilities" (Sherman \& Sherman, 2013). Thus, only about $0.03 \%$ of the examined papers deal with the topic of mobility and accessibility in the context of cognitive disabilities. The open inquiries yielded some further studies published in journals beyond the special needs discourse and thus did not end up in the main body of research. At any rate, the count of contributions on the topic of mobility and accessibility in the context of cognitive disabilities remains marginal. The additional contributions are incorporated into the body of relevant texts. Nevertheless, the necessity of combining quantitative and qualitative methods becomes apparent, as only such multi-method approaches guarantee that all relevant contributions are included into the body of research.

\section{The concept of (cognitive) disabilities - the need for a theoretical foundation}

In their qualitative work, Bitterman and Baldwin Hess (2008) engage with the concept of bus rapid transit (BRT), a relatively new form of American public transit. In this context accessibility to the authors means that busses are accessible to all people, independent of age, physical and cognitive abilities (Bitterman \& Baldwin Hess, 2008, p. 445).

It is noteworthy that their concept of accessibility lacks any apparent theoretical recourse. Rather, the authors identify a practical necessity to make the proliferating BRT systems accessible for all people and refer in this context to the concept of universal design (Bitterman \& Baldwin Hess, 2008, p. 445).

Based on the seven principles of universal design, equitable use, flexibility in use, simple and intuitive, perceptible information, tolerance of error, low physical effort, and size and space for approach and use (Connell et al., 1997), Bitterman and Baldwin Hess (2008) suggest an approach of planning and assessing BRT systems (pp. 456-457).

Sherman and Sherman (2013) also opt for a qualitative approach, though their research area is construed broader. Accordingly, they conceptualize accessibility as a basic human right, which comprises everyday access to the built environment as well as a life as an autonomous individual (p. 271), and consequently derive accessibility from a juridical perspective. Concretely, they cite the Americans with Disabilities Act (ADA) as well as the Convention on the Rights of Persons with Disabilities (CRPD) (p. 271).

The authors problematize various forms of potential barriers for people with cognitive disabilities. For example, insufficient financial resources (both individual and systemic), lack of personal planning, and insufficient transport options may constitute barriers (pp. 273-274). In addition, people with cognitive disabilities often encounter abrasive attitudes (p. 273). Ultimately, ignorance and incomprehension on the part of planning experts further curtails barrier-free utility (pp. 274-275).

At a basic level, both studies show a certain deficit of theoretical referencing, which is quite common in dealing with accessibility (not merely in the context of cognitive disabilities), thus indicating the principle need of a theoretical foundation of this (ambivalent) term.

\section{Participation of people with cognitive disabilities}

Both papers indicate that while during planning processes potential needs of physical assistance are considered, the potential needs of cognitive assistance are neglected (Bitterman \& Baldwin Hess, 2008, p. 447; Sherman \& Sherman, 2013, p. 274). Likewise, the ADA offers rather indistinct guidelines regarding people with cognitive disabilities (Bitterman \& Baldwin Hess, 2008, p. 447).

These insights are congruent with the previous results of my study in which I also demonstrate that accessibility is only seldom theorized in the context of cognitive disabilities (see also Trescher, 2018a, b). Bitterman and Baldwin Hess (2008) state that different aspects of the bus system, such as complicated graphics, are not functionally 
useful for people with cognitive disabilities (p. 452). Though this statement seems comprehensible in principle, its validity is diminished however, as no people with cognitive disabilities were incorporated into the examination neither as participating research subject, nor as researched object.

Thus, one result of the literature review reveals an overall lack in participatory research, on the one hand, and a direct examination of people with cognitive disabilities, on the other. From this follows the requirement of respective qualitative research.

\section{Perspective of Inclusion?}

Though neither study incorporates self-advocates, both nonetheless recognize this vacancy and demand the inclusion of end users into the planning process (Bitterman \& Baldwin Hess, 2008, p. 458; Sherman \& Sherman, 2013, p. 275). Accordingly, Bitterman and Baldwin Hess (2008) suggest an approach of planning and assessing BRT systems that includes self-advocates (p. 450). In this regard, the critical question arises as to why they do not already adhere to this approach in their own study. At any rate, it is commendable that the authors identify this vacancy, which increases awareness in the research community and normalizes the inclusion of self-advocates particularly regarding inclusionary potential developments.

Sherman and Sherman (2013) regard a multi-disciplinary approach (p. 273) as well as the education of planning experts as necessary measures to advancing accessibility in the realm of mobility (p. 275). They notice further need for action in personal assistance and planning (p. 273) and emphasize that inclusion is a reciprocal process that requires action of both people with and without disabilities (p. 272). The underlying concept of inclusion as a practice of negotiation seems comprehensible, though it may not be consequently adhered to in the context of the study. There is continued need for action, both in terms of practice and research.

\section{On the ambivalence of 'training'}

Sherman and Sherman (2013) refer to the implementation of training programs for using means of public transport in the USA (p. 274) and the testing of technical GPS equipment as an aid to orientation in Great Britain (Davies, Holloway, \& Wehmeyer, 2010; see also Sherman \& Sherman, 2013, p. 274), as prospective developments towards a more accessible mobility for people with cognitive disabilities. These 'trainings' are quite ambivalent, for though in some instances they may certainly contribute towards extending mobility competences, they declare the lack of accessibility, to some extent, as an individual problem, which can be mitigated through 'training'. This is indicative of an underlying problematic that coincides with 'accessibility' and a respective engagement. The practical goal of such training is to empower people with cognitive disabilities to utilize public transport. However, this should lead one to conclude that the former amounts to accessibility. Accessibility (at least to the concept here developed) aims at transforming social space, not the person. Moreover, dependency of people with cognitive disabilities to training as well as its content, frequency, etc. is problematic. Accordingly, mobility is experienced through a kind of needle eye constructed by outsiders (see also Trescher \& Hauck, 2017).

\section{Focus on public transport}

One problematic previously not discussed in this way (including the studies of Bitterman \& Baldwin Hess, 2008 and Sherman \&Sherman, 2013) is that in many smaller municipalities barriers (among other things) emerge due to a lack of differentiated public transport networks and, so that a massive dependency on automobiles - and their drivers - and/or (often insufficient) monetary resources persist (see also Trescher, 2015, p. 137). Focusing on public transport networks is problematic, since it precludes an examination of other forms of mobility (for instance, pedestrian, bicycle, or automobile). Specifically, discussing the question of why people with cognitive disabilities cannot commonly earn their driver's license (cf. Monninger \& Tsakarestos, 2010, p. 281) would certainly be interesting, particularly against the background of some individuals' concrete wish of learning how to drive (documented, for example, in Trescher, 2017a, p. 150). In the context of my study "Accessibility and cognitive disabilities" one interviewee notes: "Actually I would have liked to get my driver's license, but it didn't work out, because you need to be able to read"(02-04). It seems, therefore, that to test existing public transport systems in terms of accessibility does not suffice, but rather that it is necessary to recognize the enmeshment of the mobility problematic with many areas of life and to examine its complexity. What is needed in this context is qualitative research.

\section{Talking about Accessibility - Interviewing People with Cognitive Disabilities}


Aside from the literature review, additional semi-structured interviews were conducted with people with cognitive disabilities who are addressed as expert self-advocates. The aim of this interview study was, to gain their insights into the topic and thus to contrast the results of the literature review as well as to document experiential barriers and, in some cases, existing facilities for support. The reasoning behind this approach is that barriers need to be experienced in life practices and identified accordingly before they can be deconstructed. The survey of interviews focuses on Germany so far and should therefore be considered as introductory research, which gestures towards the need for a larger scale, international study. The semi-structured interviews with experts addressed the topic of accessibility. After an initial open question, eight areas were focused: leisure, work, school/ education, habitation, daily routine, political participation, institutions/ agencies/ bureaucracies, social areas/ mobility. Thus, the guidelines are semi-standardized since they entail both open-ended and closed questions (cf. Lamnek, 2010, p. 107; Friebertshäuser \& Langer, 2010, p. 439; Trescher, 2015, p. 59ff). According to this approach, 60 people with cognitive disabilities were located countrywide (at work, in assisted housing, at home, at events) and interviewed about the topic ${ }^{4}$. This first survey is meant to be extended to also conduct (local) research internationally, so that the challenges and suggestions for improvement of people with cognitive disabilities can be collected on site and made accessible.

The interviews are analyzed using a qualitative-content analytical method (cf. Mayring, 2010; on the application see Trescher, 2015, p. 74ff.) At first glance, the results demonstrate the extent and diversity of problematics in the context of accessibility from a perspective of self-advocates. Of 60 persons with cognitive disabilities interviewed in Germany, 46 have spoken about the topic of 'mobility'. The insights from these interviews, which must be characterized as introductory, illustrate once more the research value and advancement that occurs when people with cognitive disabilities are included as experts of their own matters. The many and reflected suggestions towards a more accessible use of public transport attest to this claim. Subsequent studies should build on this and make comprehensive insights into the daily routines of people with cognitive disabilities (for instance, using interviews, observations, and participant field research) a core aspect in their methodological setting (see also Trescher, Hauck, \& Börner, 2017).

\section{Do you use public transport?}

Many interviewed persons who frequently use means of public transport report that they do so without any problems, as they "know their way around"(02-04), know where to exit, or "know the schedule by heart"(02-07). In sum, the interview analysis yields that about $63 \%$ of interviewees use public transport frequently and independently. A significantly lower share (ca. 19\%) of interviewees partially or seldom uses public transport, while $17 \%$ never uses these means. These numbers compare to overall public transport statistics in Germany, whereby only $12.6 \%$ of interviewed persons never use public transport (see Statista, 2017). At a basic level, the question of being able to navigate an unfamiliar city arises, as many interviewees face (in some circumstances) the problem of being particularly dependent on their current residence. Moving to a different city becomes a larger obstacle (at least potentially) since they only seldom use public transport. Mobility, in this view, concerns not only daily movement within a place of residence, but also entails the appropriation of new residences and living spaces. Accessibility and mobility must therefore be theorized and researched accordingly.

\section{Why do you (not) use public means of transport? What difficulties arise?}

Many interviewees, even though reasons vary, avoid public transport from a kind of uncertainty, which may in some cases be frightening. Accordingly, one interviewee notes: "I don't use the bus, I don't dare to by myself"'(02-10). Another person does not use public transport, since she "can't read well"(01-07) and therefore has trouble reading the schedule. She says: "Some routes I can do by myself, but it's a problem when the trains don't come, then I can't read when the next one arrives and where I have to go"(01-07).

Another reason for not using public transport is that persons are picked up by a special rideshare service and taken home, so that for them, according to the reports, there is no need to use public transport. This is especially concerning, as the only (farther, non-pedestrian) routes outside of their homes that these persons seem to undertake are the ones to and from work.

\footnotetext{
${ }^{4} \mathrm{~A}$ formal ethical approval was obtained. The Letter of informed consent was written in easy language to ensure that the interviewed persons with cognitive disabilities would understand it. In addition, they could ask questions and the consent could be read aloud to them. At this stage, I would like to sincerely thank all persons who agreed to an interview!
} 
Visiting friends, engaging in leisure activities, or going on trips, are not considered in the context of public transport and, therefore, either do not happen entirely or they are only undertaken using rideshare services (professional or private). This considerably constrains the possibilities of autonomous mobility, which is problematic since mobility is a 'basic need and a precondition for a self determined life and participation in community living' (Tillmann \& Haveman,2010, p. 287; see also Tillmann, 2015). Consequently, '[1]imitations in mobility may affect physical, social, and psychological well-being' (Wasfi\& Levinson, 2006, p. 1; see also Blais \& El-Geneidy, 2004). Another obstacle regarding the use of public transport is financial, that is a result of financial challenges, which many people with cognitive disabilities encounter. One interviewee recounts: "I mostly use my bicycle, because public transport is too expensive for me. I can't afford it"(03-05). Most people with cognitive disabilities in Germany work in so-called sheltered workshops. On average, they make $181 €$ per month (BAG WfbM, 2016), which means that public transport tickets are not consistently affordable. Further difficulties arise for some, because they live in a provincial area in which the frequency of public transport is low and connections into surrounding (larger) cities are not well-developed. An autonomous mobility is thus complicated for all residents in this area.

\section{What are your suggestions to improve access to means of public transport?}

The interviews result in several suggestions about how to deconstruct barriers in the context of mobility. One person proposes to employ accompanying personnel in the vehicles of public transport to assist with entering and exiting as well as with ticket purchases and as a point person whenever issues arise. Other persons note the need for improvement in terms of arranging schedules and suggest making them easier as well as to select larger and more legible font. One interviewee recommends installing voice casting at stops to read the schedule and announce the next connections.

These recommendations are largely congruent with insights from the (partly listed) studies on the topic of mobility and cognitive disabilities (see Bitterman \& Baldwin Hess, 2008; Davies et al., 2010, p. 455ff; Kleinbach, 2009, pp. 39-40; Monninger et al., 2012, p. 55ff; Monninger \& Tsakarestos, 2010, pp. 285-286; Wasfi\& Levinson,2006; Yalon-Chamovitz,2009, p. 396ff). It remains to be seen, why (evidently) these results are not included widely in designing and developing schedules. In addition, some of the interviewees express suggestions regarding the physical use and accessibility of public transport vehicles. One person, for example, considers boarding aid useful, as she sometimes uses a walker, which makes it difficult to board the bus. Another person reports that she does not like when the tram is "so crowded"(01-04) and therefore suggests offering increased service. Thus, matters of accessibility in the context of cognitive disabilities should not exclusively focus on the areas of reading/comprehension, but rather that barriers beyond that are experienced and should accordingly be eliminated.

\section{Discussion and prospect: Perspectives on accessibility in the context of cognitive disabilities}

The context of accessibility should not be reduced to finding 'solutions' - this is a key insight of my study. Rather, it should be considered that multiple aspects (which may be ambivalent) interact and that there is a need to tackle overarching problems, such as a life under the protectorate of disability support, whose institutions in many ways unfold as disabling practices on the 'assisted' subjects (see also Trescher,2017a). Respectively, matters of accessibility and cognitive disabilities cannot be answered in a one-dimensional way, with a simple demand of 'more' accessibility, that does not suffice to conceptualize accessibility in such a way. Accessibility and barrier-free access to all areas of life is situated in the ambivalent empowerment and enabling of people with cognitive disabilities, on the one hand, and the deconstruction of barriers in a shared life world. Accessibility as well as the respective discourse reflects on the ambivalence between 'being disabled' and 'becoming disabled' - a dichotomy which by the way also affects research institutions that identify and thus reproduce a certain group of persons targeted as barriers are investigated (and deconstructed) (see Windisch, Rohrmann, \&Düber, 2015, pp. 397-398; Dederich,2012, p. 110ff). In general, one should recall that accessibility does not equate to participation and inclusion. Getting rid of (potential) barriers does not necessarily result in previously excluded persons now having unrestricted participation, since non-participation in a shared life world is characterized by a (sometimes ambivalent) practice of negotiations, which is not entirely congruent with 'accessibility'. Further research, as indicated by my study and the aforementioned research demands, must be based on empirical investigations that engage the field qualitatively and internationally and address the guiding question of the types of barriers people with cognitive disabilities encounter in their lives. At least one part of such an investigation should address to what extent people with cognitive disabilities encounter barriers as a result of entirely inaccessible practices. 
In terms of mobility, as the interviews reveal, this occurs, among other instances, due to ties to a special needs ride share, but applies to almost all areas of life, for instance, in terms of financial services. Many people with cognitive disabilities are unable to experience the accessible ATM, because they often do not oversee their finances, but rather receive allowances in their institution (see Trescher, 2017d, p. 109) or they receive money for the weekly needs in cash from their legal guardians (as is the case with one interviewee). This example illustrates that it may certainly be reasonable to arrange for an 'accessible' ATM (or public transport schedule), but, as stated above, not to assume that 'participation' follows automatically. Accessibility and less barriers are however a condition for participation and thus they must be positioned, in theory and practice, in the focus of academic discourse.

\section{Acknowledgements and funding details}

The study "Accessbility and cognitive disabilities", which forms the basis for the paper at hand, is funded by the German Bundesministeriumfür Arbeit und Soziales (Federal Ministry for Labor and Social Affairs) and is conducted in close consultation with the disability support institutions Bundesverb and Lebenshilfee.V as well as Lebenshilfe Frankfurt am Main e.V.

\section{References}

BAG WfbM.(2016).Durchschnittliche monatliche Arbeitsentgelte 2012-2015. www.bagwfbm.de/file/1053/ (accessed August 20, 2018).

Blais, D., \& El-Geneidy, A. M. (2014). Better living through mobility: the relationship between access to transportation, well-being and disability. Paper presented at the 93rd Annual Meeting of the Transportation Research Board, Washington, DC.

Bitterman, A., \& Baldwin Hess, D. (2008). Bus rapid transit identity meets universal design. Disability \& Society,23(5),445-459.

Connell, B. R., Jones, M., Mace, R., Mueller, J., Mullick, A., Ostroff, E., Sanford, J. Steinfeld, E., Story, M., \&Vanderheiden, G. (1997). The principles of universal design: Version 2.0. Raleigh, NC: The Center for Universal Design.

Davies, D. K., Stock, S. E., Holloway, S., \&Wehmeyer, M. L. (2010). Evaluating a GPS-based transportation device to support independent bus travel by people with intellectual disability. Journal of Policy and Practice in Intellectual Disabilities, 10(4), 454-463.

Dean, E. E., Fisher, K.W., Shogren, K. A., and Wehmeyer, Michael L. (2016). Participation and intellectual disability: a review of the literature. Intellectual and Developmental Disabilities,54(6), 427-439.

Dederich, M. (2012). Ästhetische und ethische Grenzen der Barrierefreiheit. InA. Tervooren\& J. Weber(Eds.), Wege zur Kultur (pp. 101-115). Köln: Böhlau.

Devas, M. (2003). Support and access in sports and leisure provision. Disability \& Society, 18(2), 231-245.

Foucault, M. (1972). The Archaeology of Knowledge and the Discourse on Language. New York: Pantheon Books.

Friebertshäuser, B., \& Langer, A. (2010). Interviewformen und Interviewpraxis. InB. Friebertshäuser, A. Langer,\& A. Prengel (Eds.),Handbuch Qualitative Forschungsmethoden in der Erziehungswissenschaft, (pp. 437-455). Weinheim: Juventa.

Heck, H. (2012). Barrieren. In I. Beck \& H. Greving (Eds.),Lebenslage und Lebensbewältigung, (pp. 328-333). Suttgart: Kohlhammer.

Hüllemann, U., Reutlinger, C., \&Deinet, U. (2016). Aneignung als strukturierendes Element des Sozialraums. In F. Kessl\& C. Reutlinger (Eds.), Handbuch Sozialraum, (n. p.). Wiesbaden: Springer VS.

Kastl, J. M. (2010). Einführung in die Soziologie der Behinderung. Wiesbaden: Springer VS.

Kleinbach, K. (2009). Wo geht's hin? Im Reutlinger Stadtverkehr. Teilhabe,48(1), 37-43.

Kurzenberger, S., Niehoff, U., Walther, H., \& Sack, R. (2012). Barrierefreiheit für Menschen mit kognitiver Beeinträchtigung - Ergebnisse einer Befragung.Teilhabe,51(3), 121-126.

Lamnek, S. (2010). Qualitative Sozialforschung (5th ed.). Weinheim: Beltz.

Mayring, P. (2010). Qualitative Inhaltsanalyse. Grundlagen und Techniken (11th ed.). Weinheim: Beltz. 
Monninger, D., Tilmann, V., Kvas, S., Hertrampf-Müller, U., Roosen, H., Arnold, T., Kupsch, A., Kloth, H., Busch, F., Stöppler, R., \&Haveman, M. (2012). Verbundprojekt MogLi - Barrierefreier Schülerverkehr. Gemeinsamer Schlussbericht. http://edok01.tib.uni-hannover.de/edoks/e01fb13/742414655.pdf(accessed August 20, 2018).

Monninger, D., \&Tsakarestos, A. (2010). Physical and psychological barriers in public transportation for school children with intellectual disabilities. In V. P. Prasher (Ed.), Contemporary Issues in Intellectual Disabilities (pp.281-286). New York: Nova Sciences.

Nind, M., \& Seale, J. (2009). Concepts of access for people with learning difficulties: towards a shared understanding. Disability \& Society,24(3), 273-287.

Shakespeare, T., \& Watson, N. (2001). The social model of disability: an outdated ideology? Research in Social Science and Disability, 2(1), 9-28.

Sherman, J., \&Sherman, S. (2013). Preventing mobility barriers to inclusion for people with intellectual disabilities.Journal of Policy and Practice in Intellectual Disabilities, 10(4), 271-276.

Statista (2017). Umfrage zur Nutzungshäufigkeit des ÖPNV innerhalb Deutschland im Alltag im Jahr 2017. https://de.statista.com/statistik/daten/studie/714824/umfrage/umfrage-zur-nutzung-des-oepnv-indeutschland/ (accessed August 20, 2018).

Stock, S. E., Davies, D. K., Wehmeyer, M. L., \&Lachapelle, Y. (2011). Emerging new practices in technology to support independent community access for people with intellectual and cognitive disabilities. Neurorehabilitation, 28(3), 261-269.

Swain, J., French, S., Barnes, C., \& Thomas, C. (2004). Disabling barriers, enabling environments. London: Sage. Tervooren, A., \& Weber, J. 2012. Einleitung: Barrieren wahrnehmen, verstehen und abbauen. In A. Tervooren\& J. Weber (Eds.), Wege zur Kultur(pp. 11-26). Köln: Böhlau.

Tillmann, V. (2015). Teilhabe am Verkehrssystem. Wiesbaden: Springer VS.

Tillmann, V., \&Haveman, M. (2010). Public transportation as a means of social integration for school children with intellectual disabilities. In V. P. Prasher (Ed.),Contemporary Issues in Intellectual Disabilities(pp. 287-289). New York: Nova Sciences.

Trescher, H. (2018a). Barrierearme Mobilität und kognitive Beeinträchtigung. Stand der Forschung. Teilhabe,57(2), 63-67.

Trescher, H. (2018b). Kognitive Beeinträchtigung und Barrierefreiheit. Eine Pilotstudie.Bad Heilbrunn: Klinkhardt, im Erscheinen.

Trescher, H. (2017a). Behinderung als Praxis. Biographische Zugänge zu Lebensentwürfen von Menschen mit 'geistiger Behinderung'.Bielefeld: transcript.

Trescher, Hendrik (2017b). Disabling Practices. Cogent Social Science3(1), online.

Trescher, Hendrik (2017c). Inclusion as Critique. Deconstructionist Approaches Exemplified through 'Care' of People with Cognitive Disabilities in Germany. International Journal ofSocial Science Studies, 5(8), 3343.

Trescher, H. (2017d). Wohnräume als pädagogische Herausforderung. Lebenslagen institutionalisiert lebender Menschen mit Behinderung (2nd ed.). Wiesbaden: Springer VS.

Trescher, H. (2015). Inklusion. Zur Dekonstruktion von Diskursteilhabebarrieren im Kontext von Freizeit und Behinderung. Wiesbaden: Springer VS.

Trescher H., \& Hauck, T. (2017). Raum und Inklusion. Zeitschrift für Inklusion,11(4), online.

Trescher, H., Hauck T., \& Börner, M. (2017). Auf dem Weg zu Inklusion? - 'Busfahren' als Praxis ethnographischer Inklusionsforschung.Vierteljahresschrift für Heilpädagogik und ihre Nachbargebiete, $86,250-252$.

Wasfi, R., \& Levinson, D. (2006). The transportation needs of people with developmental disabilities. Center for Transportation Studies, University of Minnesota.

Windisch, M., Rohrmann, A., and Düber, M. (2015). Barrierefreie Partizipation - eine Quintessenz. In M. Windisch, A. Rohrmann, \&M. Düber (Eds.),Barrierefreie Partizipation(pp. 396-414). Weinheim: BeltzJuventa.

Yalon-Chamovitz, S. (2009). Invisible access needs of people with intellectual disabilities: a conceptual model of practice. Intellectual and Developmental Disabilities, 47(5), 395-400. 